\title{
PALAVRA E PODER: \\ CONSIDERAÇÕES SOBRE O ESCRAVO MUDO EM “A GLORIOSA FAMÍLIA - O TEMPO DOS FLAMENGOS”, DE PEPETELA
}

\section{WORD AND POWER: \\ CONSIDERATIONS ABOUT THE MUTE SLAVE IN "A GLORIOSA FAMÍLIA - O TEMPO DOS FLAMENGOS”, DE PEPETELA}

Mariana Sousa Dias ${ }^{1}$

Resumo: O objetivo deste trabalho é analisar os processos de silenciamento, bem como de possibilidades de fala do subalterno no romance "A Gloriosa Família - O tempo dos flamengos", do angolano Pepetela. A partir do narrador mudo (ou emudecido), como o falar, o calar e o criar são elementos essenciais à dinâmica de elaborações discursivas que, orquestradas pelas conveniências das relações de poder, legitimam e perpetuam a dominação dos sujeitos historicamente marginalizados. Acreditamos que o narrador, como estratégia artística e estética principal da obra, confirma-se como transposição metafórica das possibilidades de fala em meio ao silenciamento imposto pelo colonizador.

Palavras-chave: Angola; Pepetela; subalterno; silenciamento; metaficção historiográfica.

Abstract: The objective of this work is to analyze the processes of silencing, as well as speech possibilities of the subordinate in the novel "A Gloriosa Família - O tempo dos flamengos", by the Angolan Pepetela. The silent (or muted) narrator, such as speaking, silencing and creating are essential elements to the dynamics of discursive elaborations that, orchestrated by the conveniences of power relations, legitimize and perpetuate the domination of historically marginalized subjects. We believe that the narrator, as the artistic and main aesthetic strategy of the work, is confirmed as metaphorical transposition of the possibilities of speech amid the silencing imposed by the colonizer.

Keywords: Angola; Pepetela; subaltern; silencing; historiographic metafiction.

\section{Introdução}

Com intensa produção romanesca, iniciada na década de 1970, Pepetela representa para Angola um dos mais proeminentes nomes quando se considera o projeto de reescrita do país e de suas gentes, seja devido à quantidade de títulos publicados, seja devido ao notável acolhimento da crítica especializada, evidenciado a partir do recebimento de homenagens como

\footnotetext{
${ }^{1}$ Doutora em Estudos de Literatura pela Universidade Federal Fluminense. Atualmente, é Professora Efetiva do Colégio Pedro II, Campus Engenho Novo II e Tutora de Literaturas Africanas 2, disciplina do curso de curso de Letras da Universidade Federal Fluminense - CEDERJ. Seu desenvolvimento na área de Letras, com ênfase em Literaturas de Língua Portuguesa, é centrado nos seguintes temas: Literatura Comparada; Literatura, História e Memória; Literatura e outras artes; Ensino de Literaturas de Expressão em Língua Portuguesa; Ensino de Língua Portuguesa; Ensino de Produção Textual; Educação e Transdisciplinaridade. E-mail: maraianasousadias@yahoo.com.br
} 
o Prêmio Camões, em 1997, e o Prêmio Internacional da Associação de Escritores em Língua Galega, em 2007. Conhecida por trabalhar tanto a história quanto a ficção como novos loci enunciativos, a obra pepeteliana é reveladora do comprometimento do autor quanto a um projeto de angolanidade, considerando a factualidade histórica, no seu confronto com a idealidade cultural e histórica para encetar uma reinterpretação fundadora, a partir de espaços, personagens e vivências que transitam desde a organização do Império Lunda ao desencanto pós-independência.

Por meio da obra Pode o subalterno falar?, a pesquisadora indiana Gayatry Spivak discursa sobre os silenciamentos impostos àqueles que pertencentem às camadas mais baixas da sociedade, constituídas pelos modos específicos de exclusão dos mercados, da representação política e legal, e da possibilidade de se tornarem membros plenos no estrato social dominante (Cf. SPIVAK, 2010, p..12). Nesse sentido, as vozes de tais sujeitos apresentam-se predominantemente intermediadas, tanto nos documentos históricos quanto nas produções artísticas, por meio de outrem. Devido às impossibilidades de autorrepresentação, jogos estéticos e discursivos podem ser utilizados a fim de que o subalterno seja ouvido.

O papel do escritor que se alinha ao campo contra-hegemônico, portanto, é uma tentativa de desviar o curso da história, mostrando que a subalternidade não é uma categoria fixa ou uniforme, ao contrário do que veiculavam os discursos coloniais. Como explica Bhabha:

Um aspecto importante do discurso colonial é sua dependência do conceito de
"fixidez" na construção ideológica da alteridade. A fixidez, como signo da diferença
cultural /histórica/racial no discurso do colonialismo, é um modo de representação
paradoxal: conota rigidez e ordem imutável como também desordem, degeneração e
repetição demoníaca. Do mesmo modo, o estereótipo, que é a sua principal estratégia
discursiva, é uma forma de conhecimento e identificação que vacila entre o que está
sempre "no lugar", já conhecido, e algo que deve ser ansiosamente repetido.
(BHABHA, 2007, p. 105).

Nos discursos pós-coloniais, essa fixidez é questionada por um olhar que, ao dialogar com os discursos europeus, reinscreve e questiona a construção de alteridades "através das condições de contingência e contrariedade que presidem sobre a vida dos que estão na minoria" (BHABHA, 2007, p. 21). O processo pelo qual o discurso imperial fabrica o outro para conferir aos colonizados o status de objeto, entretanto, pode apresentar fraturas que, se não possibilitam a expressão direta do sujeito subalterno, ao menos apontam para a possibilidade de encenações que denunciem a opressão discursiva. Dessa forma, o intelectual não pode "falar pelo subalterno, mas pode lutar contra a subalternidade, criando espaços nos quais possam se articular" (SPIVAK, 2010, p. 09). 
É neste sentido que A gloriosa família: o tempo dos flamengos, por meio de um narrador escravizado, mudo e analfabeto, articula-se tanto ao questionamento de Spivak, rompendo com o estigma da impossibilidade do subalterno, quanto à perspectiva de Bhabha acerca da fixidez como um elemento a ser questionado quando analisamos os processos de construção da diferença.

\section{O (não) silenciamento do escravo como estratégia metaficcional}

Pepetela, em A Gloriosa Família, publicado em 1997, faz uma grande viagem ao passado, retomando o século XVII, mais especificamente de 1642 a 1648, os sete anos de invasão holandesa às terras onde hoje se situa a capital Luanda. Quando conquistaram o nordeste brasileiro, logo perceberam a importância que a exploração de escravos tinha para a economia, afinal, “sem negros não há Pernambuco e sem Angola não há negros.” (PEPETELA, 1999, p.283)

Os portugueses, após a invasão, viram-se obrigados ao refúgio no interior, mais especificamente em Massangano. A narração gira em torno de Baltazar Van Dum, holandês envolvido com tráfico de escravos e residente em Luanda desde 1616. Van Dum, estimado por seus compatriotas, busca mediar as relações pessoais e sociais tanto com os holandeses quanto com os portugueses, para que, assim, não sofra represálias.

O conturbado período nos é apresentado por um escravo mudo, qualidade que opera uma ressignificação de seu lugar; ainda que destituído de liberdade, acompanha sempre seu dono, Baltazar, e está em posição privilegiada, visto que se torna testemunha de uma série de fatos. Além de narrar o que presencia, pode ainda, por meio do exercício da imaginação, criar outros acontecimentos, transformar Van Dum e seus filhos em personagens para, assim, construir um relato vigoroso sobre a família, num exercício de preenchimento dos vazios epistemológicos.

À exceção dos capítulos primeiro e décimo, todos os capítulos estão antecedidos por um prólogo constituído por um excerto da História Geral das Guerras Angolanas, de Antônio de Oliveira Cadornega. O alferes é uma figura fundamental à composição do romance, uma vez que se transforma, também, em personagem. Se os portugueses deram a Cadornega o prestígio de um historiador, na instância narrativa é o escravo mudo que detém a centralidade da fala. A 
historiografia, como versão totalizadora e homogênea, dá lugar aos questionamentos quanto à seletividade e os jogos de poder que a perpassam.

Foi por meio do registro histórico e da escrita que se propagaram os feitos grandiosos dos heróis portugueses, também representado, portanto, como instrumento dominador:

\begin{abstract}
- Diga-me, senhor alferes. Falou em registar por escrito o que vai observando. Está a escrever um livro sobre estes acontecimentos?

- Ainda não. Por enquanto, só tenho apontamentos dispersos. Penso contar a história heroica dos portugueses nesta terra, desde a fundação da cidade de Luanda. Por isso pergunto detalhes aos que viveram as coisas e registo o que me contam.

- E vai apresentar o governador Sottomayor da maneira como fala dele aqui entre amigos? Porque li algumas crônicas e até poemas sobre os reis e heróis de Portugal, que só cantam coisas sublimes e grandiosas, como se não existissem as menos gloriosas.

- Chega a ser uma questão moral. Se escrevo sobre as grandezas de Portugal, como posso contar as coisas mesquinhas? Não, essas ficam no tinteiro, pois não interessam para a história. Será necessário saber interpretar a crônica. Personagem que não aparece revestida de grandes encômios é porque não prestava mesmo para nada e só o pudor do escritor salvaguarda sua memória. Assim se tem feito, assim deve ser. (PEPETELA, 1999, p. 269 - Grifos nossos).
\end{abstract}

O trecho nos revela não apenas a parcialidade do discurso histórico, mas a própria necessidade de reflexão crítica por parte do leitor, visto que Cadornega menciona a necessidade de interpretação do texto e, articuladamente, de seus contextos de produção e de recepção. A narrativa nos indica que o jovem alferes, está não somente em início de carreira militar, mas também risca as primeiras linhas como historiador e poeta:

E vi alguns a defender energicamente o governador, como por exemplo o jovem soldado Antônio de Oliveira Cadornega, que tinha chegado a Luanda no mesmo barco de Pedro César e que era conhecido pelo "Segundo Camões", por andar sempre com um caderninho a tomar notas, a fazer poemas. (PEPETELA, 1999: p. 41)

Ao apropriar-se da figura de Cadornega para estabelecer uma aproximação entre historiografia e literatura, Pepetela opera diretamente com as margens que envolvem Literatura e História como produções discursivas e, portanto, dotadas de parcialidade, trabalho recorrente em sua produção romanesca. $\mathrm{O}$ alferes é historiador, mas também poeta, e suas facetes, no romance, não estão dissociadas. Notamos, assim, que o discurso historiográfico, predominantemente tomado como verdade absoluta, mostra-se não tão distante do discurso literário, visto que se utiliza da palavra para elaborar e perpetuar determinada perspectiva dos fatos.

A epígrafe do romance estabelece uma curiosa ponte com o tom irônico da ficção de Pepetela; embora se trate de um excerto da História geral das guerras angolanas, de Antônio de 
Oliveira Cadornega, a pretensa seriedade do discurso histórico mostra-se imbuída de um tom levemente cômico ao apresentar Baltazar Van Dum:

\begin{abstract}
Em a cidade assistia hum homem por nome Baltazar Van Dum, Flamengo de Nação, mas de animo Portuguez que havia ido dos primeiros Arrayaes para a Loanda com permissão de quem governava os Portuguezes, o qual esteve posto em risco de o matarem os Flamengos (...) Hum Cidadão, por ver se por sua via podiamos haver algumas intelligencias de que passava entre o Flamengo, (...) vendo o perigo em que estava, o avizou secretamente, em como o hião a prender, e o porquê; que viesse logo dar parte ao Senhor Director. (...) Chegado que foi ao Collegio onde o Director rezidia, lhe deo parte de haverem chegado aquelles Negros de Masangano com a carta ainda fechada; olhou o Director para elle, dizendo-lhe ah! Van Dum, Van Dum, Van Dum! A tua Cabeça, a tiveste mui arriscada... (PEPETELA, 1999, p. 9)
\end{abstract}

O trecho vai ao encontro do tom sarcástico do próprio narrador, visto que, na conjugação criada entre a citação e a narrativa propriamente dita, a feição incomum do trecho de Cadornega dialoga com o olhar irônico do escravo mudo para empreender um projeto de dessacralização do cânone que sustenta o discurso histórico oficial.

Jurado de morte por traição ao seu povo de origem, Baltazar busca reverter a situação, convencendo os dirigentes de que a situação não passa de um mal-entendido e que ele está a serviço dos novos donatários de Luanda. Ao final da difícil tarefa estava Van Dum molhado nas calças, devido ao medo de ser punido:

\footnotetext{
O meu dono começou a andar para casa e eu fui atrás, era para isso que existia. Não falou ao major da mijada que dera nos calções, devia ter vergonha. Mas era evidente. Eu não vi, quem sou eu para entrar na casa onde despacham os nobres diretores da majestática Companhia das Índias Ocidentais? Tinha uma certa curiosidade de conhecer o diretor Nieulant. Diziam ser o melhor dos dois representantes da toda poderosa Companhia, fundada para colonizar os territórios à volta do Atlântico. (PEPETELA, 1999, p.14).
}

O tom jocoso do trecho traz à tona, portanto, as limitações de um sujeito preso ao jogo de aparências, próprio daqueles que buscam manter seu status social por meio de uma pretensa austeridade. É válido notar que a epígrafe, por sua vez, não é invalidada pela narrativa ficcional, visto que entrelaça um olhar alternativo que acaba por reafirmar a perspectiva já apresentada no texto historiográfico.

O autor apresenta-nos uma impossibilidade de base essencialmente metaficcional: o narrador que, embora destituído de fala e escrita, detém o poder da palavra e conduz a apresentação dos fatos que envolvem a família Van Dum. Seu silenciamento, curiosamente, torna-se a brecha para que seja possível presenciar acontecimentos e imaginar outros, acrescentando-os aos fatos perpetuados pelo discurso historiográfico: 
Ninguém mais percebeu, só eu, mas ninguém tem o meu faro para detectar insignificâncias escondidas na cabeça das pessoas. Às vezes essas coisas escondidas não são tão insignificantes assim, acabam por explicar acontecimentos futuros. Muitas vezes tão no futuro que as ligações não se fazem, ficam escondidas em repouso, até que alguém cosa as pontas. Sucede provavelmente com certa frequência não surgir alguém com esse talento de coser pontas e o conhecimento se perde. (PEPETELA, 1999, p. 115)

O "talento para coser", portanto, estende-se aos leitores e também aos escritores, que ressignificam a história angolana para perspectivar o pós-independência como uma extensão de seus percursos e desdobramentos. Tal perspectiva é fundamental para considerarmos a subalternidade como uma construção que interessa fundamentalmente aos detentores do poder; a condução narrativa que enfoca os sujeitos ex-cêntricos em expressões artísticas, dessa forma, lança questionamentos a práticas, categorizações e julgamentos que venham a reforçar e propagam as perniciosas formas de controle produzidas pelo discurso imperialista.

Conhecedor dessa e de outras situações constrangedoras, presenciadas ou imaginadas, o escravo mudo esclarece para o leitor que está seguro quanto à possibilidade de presenciar e de narrar os fatos, já que Van Dum não o concebe na posição de testemunha:

A tropa que ia prender o meu dono descia pela Calçada dos Enforcados. Assim, nós
desencontramos, como mandara o major Tack. E o meu dono salvou a cabeça. Apenas
mijou os calções. E só ele e eu soubemos, pois o mijo deve ter pingado diretamente
para dentro das botas, que esconderam o delito. Se caísse na alcatifa do Diretor, seria
bem mais grave. E o meu dono não sabe que eu sei. Como, não sabe muitas outras
coisas. Eu sei, é o que importa. (PEPETELA, 1999, p. 33 - Grifos nossos)

Em seguida, fica claro que Van Dum ocultaria a situação:

Tive esperanças que Baltazar contasse aos amigos que tinha mijado. Ele bem fez o gesto característico, o inclinar para frente na mesa, o baixar a voz em hesitação, mas depois se ergueu com aquele sorrisinho orgulhoso que tinha, de fazer estremecer o bigode, e me desiludi. Nunca ia contar isso a ninguém, até o ocultou da mulher, não mudando de calções para que secassem clandestinamente no corpo (PEPETELA, 1999, p. 34).

Apesar de o narrador afirmar constantemente que não pretende falar de sua vida, mas sim da vida de seu dono, acaba por isso mesmo enfatizando sua marginalidade como uma condição a todo tempo confirmada pelas ações dos membros da família e dos demais personagens. Devido à pretensa incapacidade de expressão, o homem branco se considera livre para agir como bem entender, visto que o silenciamento do oprimido garantirá a permanência do opressor em posição de privilégio.

O trecho a seguir, portanto, acaba por representar a forma como o colonizador percebe o negro como um sujeito amordaçado, livrando o europeu de futuras culpabilizações: 


\begin{abstract}
- Desculpe, amigo Van Dum, mas tenho uma pergunta há anos para lhe fazer e depois sempre acontece qualquer coisa que me distrai e não a faço. Mas é a seguinte. Tem tanta confiança assim neste seu escravo mulato? Porque ele anda sempre consigo e ouve todas as conversas. Não tem medo que ele acabe por revelar algum segredo? O meu dono deu uma gargalhada que acordou os espíritos em descanso no cimo da mangueira. Olhou para o meu lado mas nem chegou a completar o movimento de modo a me encarar de frente, seria a terceira vez na vida talvez. E respondeu com o maior à-vontade, em tom até um tudo nada acima do normal:

- Não tem perigo. É mudo de nascença. E analfabeto. Até duvido que perceba uma só palavra que não seja de kimbundu. Sei lá mesmo se percebe kimbundu... Umas frases se tanto! Como pode revelar segredos? Este é que é mesmo um túmulo, o mais fiel dos confidentes. Confesse-lhe todos os seus pecados, ninguém saberá, nem Deus. (PEPETELA, 1999, p. 393)
\end{abstract}

Tal argumentação demonstra o pensamento do homem branco, pondo em evidência a crença de que o escravo seria um objeto ou animal, não uma pessoa dotada de sentimentos, atitudes ou senso crítico. Prevalece o ar de superioridade por parte dos senhores, que subestimam a humanidade e a capacidade intelectual do narrador, o que vem a ser refutado pela subversão empreendida pelo narrador no tocante ao apagamento que lhe é imposto.

Ao fazer reflexões que nos remetem à historiografia, o narrador evidencia a violência da empreitada colonialista, destacando, por vezes, o menosprezo que os europeus tinham pelos africanos devido ao fato de seus povos serem majoritariamente de culturas ágrafas:

Não sou muito versado na história dos homens, sei apenas o que o meu dono sabe e contou, o que outros lhe contaram e ouvi, coisa pouca. Mas o suficiente para entender que muito se perdeu, ao longo dos séculos, na ligação às verdadeiras causas de fenômenos aparentemente inexplicáveis. (PEPETELA, 1999, p. 115)

O analfabetismo determina a falta do registro historiográfico. A impossibilidade de produzir uma história de registro alfabético, nos moldes ocidentais, é não somente ironizada, mas denunciada por meio da construção de um narrador que não atende aos parâmetros da ciência ou da racionalidade que a história toma como norteadores.

A história carrega o silenciamento das memórias coletivas e é justamente esse tensionamento que traz significação à instância narrativa do romance estudado:

\begin{abstract}
Afinal o meu dono fazia coisas nas minhas costas, escondia-me dados importantes? (...) Abri mais os ouvidos e a partir dessa noite dormi ainda menos. A imaginação trabalhava para me entreter nas horas de espera. Grande sonso, o meu dono, não era mesmo feio trair o seu escravo de estimação? Nunca lhe pedi nada, nem mesmo a liberdade, não perco tempo nem saliva a pedir o impossível. Não merecia ao menos um pouco de transparência nos seus gestos, eu que me alimento praticamente do que vejo e oiço? (PEPETELA, 1999, p. 118).
\end{abstract}

O fato de estar afastado dos acontecimentos incomoda o narrador justamente porque ele sabe da importância dos seus relatos para a posteridade, visto que a tradição oral é um contributo da África para a história universal, "na medida em que foi uma necessidade para se estudar os 
povos africanos e que, posteriormente se tornou uma ferramenta para todos os outros povos" (PANTOJA, 2011, p. 20). Assim, o narrador se alimenta daquilo que pode ouvir e imaginar, pois tem consciência de que não pode deixar de transmitir seu testemunho:

Não é só curiosidade vã, eu tenho sentido da história e da necessidade de a alimentar, embora os padres e outros europeus digam que não temos nem sabemos o que é História. Sou muito diferente do governador Pedro César de Menezes, que deixou perderem-se todos os documentos de Luanda. (...) Depois somos nós que não temos sentido da história, só porque não sabemos escrever. Eu, pelo menos, sinto grande responsabilidade em ver e ouvir tudo para um dia poder contar, correndo as gerações, da mesma maneira que aprendi com outros o que antes sucedeu. Por isso o meu dono não tinha o direito de tentar me esconder tão magnos acontecimentos que passam na sua cabeça, mesmo se um pouco loucos. (PEPETELA, 1999, p. 119).

Os exercícios de autorreflexão do narrador partem, na maioria das vezes, através da análise do outro, levando-o não somente a entender como as relações se estabelecem e de que maneira está nelas inserido, mas também a elaborar contradiscursos de forma peculiar. A perspectiva do subjugado, cuja voz fora omitida e excluída da história oficial, vence os impedimentos processados na construção de sua identidade, pois, se apropriando do narrar, passa a ser agente e sujeito de sua própria fala.

Tão habilidoso é o escravo em sua arte de perceber os fatos que passamos a conhecer sua capacidade de conhecer as mais diferentes línguas que compõem o painel híbrido da sociedade angolana no contexto histórico apresentado:

O engraçado eram as línguas da conversa. Se era para todos perceberem e participarem, utilizavam o kimbundo. Se Baltazar queria dizer alguma coisa confidencial a Nicolau, usava o flamengo. E se Nicolau ou o meu dono se dirigiam a Diogo, para só os três se comunicarem, o português era escolhido. Complicado para quem não dominava os três idiomas. Eu estava perfeitamente à vontade. Até podiam falar castelhano ou mesmo francês, que o sentido não me escaparia. (PEPETELA, 1999, p. 114)

Uma vez que era mudo e analfabeto, condição que o privaria da comunicação, notamos que poderes desconhecidos permitem que se expresse:

Sempre achei que o meu dono subestimava as minhas capacidades. Bem gostaria nesse momento de poder falar para lhe dizer que até francês aprendi no tempo dos jogos de cartas. E que bem podiam baixar a voz ao mínimo entendível que eu ouvia sem esforço, bastando ajustar o tamanho das orelhas. Mas se tão pouco valor me atribuía, então também não merecia o meu esforço de lhe fazer compreender o contrário, morresse com a sua ideia. Uma desforra para tanto desprezo seria contar toda a sua estória, um dia. Soube então que o faria, apesar de mudo e analfabeto. Usando poderes desconhecidos, dos que se ocultam no pó branco da pemba ou nos riscos traçados nos ares das encruzilhadas pelos espíritos inquietos. Fosse de que maneira fosse, tive a certeza de o meu relato chegar a alguém, colocado em impreciso ponto do tempo e do espaço, o qual seria capaz de gravar tudo tal qual testemunhei. (PEPETELA, 1999, p. 394 - Grifos nossos) 
O trecho nos traz uma importante reflexão: ao pensarmos sobre a fala do sujeito marginalizado, devemos considerar, igualmente, a recepção dessa fala, visto que a comunicação envolve também o receptor. Pepetela nos faz problematizar, dessa forma, o posicionamento dos sujeitos contemporâneos diante dos processos de subalternidade, visto que a denúncia do emudecimento é uma proposta aberta de reflexão crítica e, sobretudo, de mobilização.

O paradoxo da mudez do escravo que tudo vê e conta é a forma de inserção da perspectiva da margem na narrativa, trazendo à tona a crueldade da ação colonialista, em especial no tocante à sujeição do negro. Seu silenciamento está ligado à naturalização do apagamento e, consequentemente, da morte física, cultural, discursiva e histórica promovida pelos portugueses durante séculos em Angola.

O escravo recorrentemente questiona-se sobre a sua utilidade, o seu lugar no meio social apresentado, o que explicita a reificação como base das relações escravagistas:

\footnotetext{
O major e o meu dono saltaram para cima dos cavalos, tive de correr para acompanhar o passo. Chegaram ao colégio, desmontaram, entraram sem cumprimentar o sentinela, nem olharam para mim. Quer dizer, era escusado me ter cansado a correr para ficar ali à porta, sem ter merecido ao menos um olhar. Como se eu não existisse. Mas existiria mesmo? (PEPETELA, 1999, p. 124).
}

Vagando pelas ruas de Luanda e por outros espaços do território angolano, na esteira de seu dono, o escravo mudo transformara-se num morto-vivo, num cazumbi capaz de fazer ressurgirem, dos mistérios da pemba, as histórias que, tal como ele, se imaginavam mortas, mas estavam apenas sufocadas. É espreitando os corredores da morte, recriando restos e revelando o desconhecido, que o discurso sem voz se fará reconhecer, questionando as versões consagradas da história e fazendo emergir sentidos marginais que se encontravam silenciados. Dessa forma, por meio do pó mágico o silêncio se transforma em palavra, ou seja, a própria arma utilizada pelo colonizador para solapar o colonizado é subvertida para trazer vida ao ponto de vista do escravo emudecido.

Como observa Ana Mafalda Leite:

Narrador personagem, a sua personalidade nunca se destaca muito ao longo da história. Tem uma breve biografia e alimenta-se das histórias dos outros, bem como de uma outra sombra, que o manipula, o autor. Irônico, atento, minucioso, este escravo liberto vagueia como um espírito às margens de todos os factos, as recônditas ilhas da imaginação de cada personagem, os esconsos lugares do saber e da informação, qual curioso Mr. Watson nas pistas de um enredo a descobrir. Só que ele já conhece o fim da intriga, e os presumíveis culpados. Ele sabe tudo, atravessa os vários campos do saber, desde a arquitetura, à política, à religião, ao amor. Um filósofo, um pensador, este escravo... Mas mais do que isso, um cronista, atento relator da História. (LEITE, 2009, p. 109 - Grifos nossos) 
A ligação entre palavra, fala e vida, bem como entre silenciamento e morte é, portanto, uma importante chave de leitura para compreendermos a construção do narrador emudecido e sem nome, ou seja, duplamente despersonalizado e "morto": uma vez que consideramos tal relação, é fundamental ressaltarmos que além de não poder falar, o escravo sequer recebe um nome próprio que lhe individualize ou humanize.

O sistema colonial gerou uma dinâmica de anonimato por meio da qual uma massa sem rosto e identidade ficou submersa a uma nuvem de discursos unívocos e grandiosos. O narrador de Pepetela é um representante legal dessa linhagem de indivíduos sem identidade. Se o escravo emudecido é uma representação do subalterno silenciado pela história, sua despersonalização se estende àqueles considerados sem nome e sem rosto pela cultura eurocêntrica, contrariamente aos grandes nomes históricos, imortalizados por meio de escritos, bustos, pinturas, datas comemorativas e homenagens diversas.

Um ponto a ser destacado, nesse sentido, é a comparação que o narrador faz entre o embarque de prisioneiros portugueses e o de escravos para o Brasil. Quando os holandeses invadem Luanda, há assassinatos, estupros, saques e outros ataques aos brancos. Alguns sobreviventes conseguem fugir para o interior, outros são capturados e enviados para Pernambuco:

\begin{abstract}
Aquela gente toda a embarcar sem nada num veleiro bastante pequeno, sem um piloto experiente e com pouca água e comida, era espetáculo de cortar o coração aos amigos. Havia alguns prisioneiros, hoje andrajosos, que tinham sido poderosos senhores e elegantes damas. Outros foram menos importantes, mas todos com posses, pois eram brancos e a cor sempre era uma garantia. (...) O espetáculo era deprimente, pois muitas mulheres choravam os maridos mortos ou perdidos pelo mato, os maridos choravam as mulheres que tinham tardado em Massangano ou Cambambe ou Muxima, as crianças choravam pelos pais, e todos choravam pelo que deixavam. (PEPETELA, 1999, p. 74-75)
\end{abstract}

Embora reconheça que o episódio seja chocante e doloroso, afirma em seguida que não havia lágrimas ou pesares quando se tratava do envio de escravos, nas mesmas condições, para serem vendidos como peças. Quando se tratava da diáspora forçada do homem branco, havia revolta e comoção; no caso do negro angolano, que durante séculos foi enviado a vários países como mão de obra, indiferença e naturalização da violência física, psicológica e cultural:

Era, no entanto, bastante diferente de uma partida de escravos. Os escravos seriam muito mais e todos acamados no mesmo compartimento, mas não me refiro ao número. Os escravos iam acorrentados e calados, numa passividade para lá do desespero. E uma partida de escravos não tinha público, só interessava ao comerciante que os despachava, ninguém pararia para ver uma chalupa cheia de escravos a caminho de um barco negreiro. Estes prisioneiros brancos conseguiam despertar pena mesmo nos que se consideravam seus inimigos. Os prisioneiros negros nem isso, só a indiferença que as coisas alheias geram. (PEPETELA, 1999, p. 75) 
De acordo com Linda Hutcheon, "a metaficção historiográfica procura desmarginalizar o literário por meio do confronto com o histórico, e o faz tanto em termos temáticos como formais" (HUTCHEON, 1991, p. 145). Nesse sentido, o romance revela faces omitidas e proporciona novas perspectivas dos fatos históricos não apenas a partir da descrição de temas ou costumes urbanos, mas pelos próprios elementos que compõem a narrativa, destacando-se, claramente a elaboração de um escravo destituído da possibilidade de fala.

De fato, o que a narrativa de Pepetela mostra é que a família de Van Dum não era tão gloriosa assim. Nascido em Bruges, de uma família católica, Baltazar, quando jovem, alistouse no exército espanhol contra os protestantes holandeses, como fuga à gravidez indesejada de uma vizinha. Após a desmobilização, "sem ter provado o gosto da guerra" (PEPETELA, 1999, p. 17), Baltazar leva uma vida ociosa e boêmia, gastando seus recursos em Lisboa, nas tabernas da beira-rio ou de Alfama. O que o leva a partir para a Angola é o desejo de enriquecimento fácil, "o sonho dessa árvore maravilhosa, que bastava sacudir para caírem as moedas de ouro" (Idem).

Chegando a Luanda, começou como agricultor, com plantações de mandioca e legumes no Bengo, até se tornar comerciante de escravos. Casa-se com "D. Inocência, filha de um pequeno soba de Kilunde" (PEPETELA, 1999, p. 21) com quem tem oito filhos vivos. Para não criar maiores problemas entre ele, tem o costume de enviar as escravas com quem tinha filhos para o Brasil, ficando apenas com as crianças, consideradas mercadorias para serem comercializadas ou utilizadas em trabalhos braçais da casa e do quintal. Baltazar, portanto, é símbolo de uma classe burguesa que mantém o prestígio por meio da adaptação aos jogos de poder e da exploração dos menos favorecidos.

D. Inocência, sua esposa, apesar de ser mais escura do que muitos escravos, tratava-os friamente e era favorável ao branqueamento da cor e dos costumes; Matilde, a feiticeira da família, não apenas engravida antes do casamento com um não-católico, como também posteriormente trai seu marido, o que se torna um escândalo; Rosário se apaixona por um escravo, Thor, o que custou a vida do rapaz; Ambrósio, por sua vez, casa-se e tem filhos com Angélica Ricos Olhos, uma prostituta estrábica; Hermenegildo o rapaz afeminado, engravida a escrava coxa Dolores; Benvindo era ridicularizado por sua voz de falsete e, por fim, Catarina, a grande paixão do narrador, era oprimida por D. Inocência e Van Dum.

Van Dum busca, no cenário hostil dos embates comerciais entre portugueses e holandeses, articular-se favoravelmente em relação às duas empresas escravocratas, para que, 
assim, possa alcançar benefício próprio. Por meio do processo de ascensão de sua família, é possível acompanhar como as campanhas de silenciamento, reificação e morte dos povos escravizados propiciaram a construção dos grandes colonialistas portugueses, visto que "o poder de narrar, ou de impedir que se formem e surjam outras narrativas, é muito importante para a cultura e o imperialismo, e constitui uma das principais conexões entre ambos". (SAID, 1995, p. 13). Dessa forma, perpetuam-se as, ironicamente nada gloriosas vozes dos conquistadores europeus e dos brancos e mestiços angolanos que, às custas da exploração do negro e da submissão às condições do momento, foram eternizados pelo registro historiográfico.

Após reconstruir o período de sete anos em disputa pelo espaço e pelas "peças" de comercialização escravista em Angola, o narrador encerra sua tarefa, no último capítulo do romance, com a reconquista do território sob domínio dos holandeses. Corre a notícia de que um importante e numeroso exército sai do Brasil para chegar a Luanda e resolver o impasse da falta de mão de obra nas terras americanas. No dia 12 de agosto de 1648, "pela manhã, que apareceram as velas brancas" (PEPETELA, 1999, p. 379), comandadas pelo senhor Salvador Correia de Sá e Benevides. Ao total, quatorze dos quinze navios que zarparam do Brasil chegaram com a quantia de quatrocentos soldados, número suficiente para retomar com alguma tranquilidade o domínio da cidade de Luanda e fazer com que os holandeses batessem em retirada, de retorno ao país de origem.

O senhor Jacinto da Câmara, vindo de Massangano logo que receberam a notícia da chegada de Salvador Correia (...) também tinha ouvido sobre os dotes de Matilde e algumas de suas profecias. Por isso perguntou:

- E é verdade o que diz a sua irmã Gertrudes muito em segredo lá em Massangano? Que a Matilde jura que os Van Dum serão uma família gloriosa?

- Tem dúvidas, Senhor Câmara?

E Matilde atirou ao velho flamengo o seu sorriso mais bonito e mais malandro. Se este não sentiu um fogo percorrer o baixo ventre é porque as velhas brasas estavam definitivamente extintas. Não as minhas. (PEPETELA, 1999, p. 406 Grifos nossos)

Se o romance apresenta um narrador que frequentemente questiona sua própria existência, o término deixa clara a confirmação de que seus sentidos, fundamentais para o desenvolvimento de percepções que apresenta acerca dos fatos e das personagens apresentadas, estão em pleno funcionamento. O narrador emudecido confirma-se ainda mais vivo do que o senhor a quem se atribui reconhecimento e importância após a finalização de seu importante e glorioso trabalho: o registro das impressões e criações marginalizadas para aqueles que, futuramente, poderiam compreendê-las. 


\title{
Considerações finais
}

A Gloriosa Família interpela o passado na interpretação do presente, bem como a efabulação na interpretação da historiografia, ressignificando a compreensão de tais instâncias de forma a partir da ruptura com percepções dicotômicas. Nesse sentido, revisita os escritos de Cadornega para pensá-los não somente como documentos, mas especialmente como crônicas, aproximando as discursividades histórica e literária.

Apresenta, ainda, como construção narrativa, um escravo emudecido que, por meio dos poderes mágicos da pemba, utiliza-se da própria arma utilizada pelo colonizador para refutá-lo: a palavra. Assim, a transposição metafórica dos tensionamentos enunciativos que envolvem palavra e poder em A gloriosa família evidencia-nos um elemento de associação entre silenciamento e morte, reconfigurada pelo narrador em palavra e vida.

É por meio da condição de trânsito entre a morte social e a vida discursiva que o escravo emudecido constrói seus relatos e contradiz as expectativas de Van Dum não somente quanto à sua capacidade testemunhal, mas, sobretudo, autoral:

\begin{abstract}
O seu rosto é um duplo de um duplo, escravo e senhor enquanto personagem, pois se alimenta da vida do patrão, escravo e autor, pois se nutre da consciência autoral. Instância ligada umbilicalmente a dois tempos, o tempo da história e o tempo do discurso, este pequeno deus narratológico transcende os limites da sua temporalidade ficcional e olha a História do seu Presente com o saber factual de um Futuro nele contido e atualizado. (LEITE, 2009, p. 113)
\end{abstract}

Além de muito atento aos casos ocorridos, sua observação lhe propicia o conhecimento dos mais íntimos detalhes. Coube ao narrador, então, a tarefa de recolher e articular os pontos soltos da história, apresentando-os ao leitor. O que percebemos, de fato, é que por se tratar de um narrador impossível, do ponto de vista histórico e, portanto, só possível na ficção.

Seja no século XVII, marcado pelas disputas entre holandeses e portugueses pelo controle do tráfico de escravos, seja na atualidade, existiram e existem pessoas que, consideradas incapazes ou não merecedoras de dizerem algo, foram silenciadas pela história. A questão que se coloca a partir da transposição metafórica estudada, portanto, parece ser não mais a impossibilidade de o subalterno poder ou não falar, mas sim a predisposição do sujeito contemporâneo a ouvi-lo e buscar compreender os mecanismos que seguem contribuindo para o apagamento das vozes marginalizadas.

\section{Referências}


BHABHA, Homi K. O local da cultura. Tradução de Eliane Lourenço de Lima Reis, Gláucia Renata Golçalves e Myriam Ávila. Belo Horizonte: UFMG, 2007.

CADORNEGA, António de Oliveira de. História geral das guerras angolanas: 1680. Lisboa: Agência-geral do Ultramar, 1972. (3 vols.). Anotações e correções de J. M. Delgado.

CHAVES, Rita \& MACÊDO, Tania. (Orgs.). Portanto... Pepetela. São Paulo: Ateliê Editorial, 2009.

HUTCHEON, Linda. Poética do pós-modernismo: história, teoria e ficção. Tradução de Ricardo Cruz Rio de Janeiro: Imago, 1991.

LEITE, Ana Mafalda. Literaturas africanas e formulações pós-coloniais. Lisboa, Colibri: 2009.

MATA, Inocência. Ficção e História na literatura angolana: o caso de Pepetela. Edições Colibri: Lisboa, 2010.

MATA, Inocência. "Pepetela: a releitura da história entre gestos de reconstrução". In: Portanto... Pepetela. CHAVES, Rita; MACÊDO, Tania. (Orgs.) São Paulo: Ateliê Editorial, 2009.

MATA, Inocência. Literatura angolana: silêncios e falas de uma voz inquieta. Lisboa: Mar além, 2001.

MEMMI, Albert. Retrato do colonizado precedido do retrato do colonizador. Tradução de Marcelo Jacques de Moraes. Rio de Janeiro: Civilização Brasileira, 2007.

PADILHA, Laura. Entre voz e letra: o lugar da ancestralidade na ficção angolana do século XX. Niterói: EDUFF, 2007.

PEPETELA. A gloriosa família - o tempo dos flamengos. Rio de Janeiro: Nova Fronteira, 1997.

SAID, Edward. Cultura e imperialismo. Tradução de Denise Bottmann São Paulo: Companhia das Letras, 1995.

SPIVAK, Gayatri Chakravorty. Pode o subalterno falar? Tradução de Sandra Reginan Goulart Almeida; Marcos Pereira Feitosa; André Pereira. Belo Horizonte: Editora da UFMG, 2010. 